\title{
Development of a Pulsed 2-micron Integrated Path Differential Absorption Lidar for $\mathrm{CO}_{2}$ Measurement
}

\author{
Upendra N. Singh ${ }^{1 *}$, Jirong $\mathrm{Yu}^{1}$, Mulugeta Petros ${ }^{1}$, Tamer F. Refaat ${ }^{2}$ and Karl Reithmaier ${ }^{3}$ \\ ${ }^{1}$ NASA Langley Research Center, MS 433, Hampton, VA 23681 USA. \\ ${ }^{2}$ Applied Research Center, Old Dominion University, Newport News, VA 23606 USA. \\ ${ }^{3}$ Science System \& Applications, Inc, Hampton, Virginia 23666 USA.
}

\begin{abstract}
Atmospheric carbon dioxide $\left(\mathrm{CO}_{2}\right)$ is an important greenhouse gas that significantly contributes to the carbon cycle and global radiation budget on Earth. Active remote sensing of $\mathrm{CO}_{2}$ is important to address several limitations that contend with passive sensors. A 2-micron double-pulsed, Integrated Path Differential Absorption (IPDA) lidar instrument for ground and airborne atmospheric $\mathrm{CO}_{2}$ concentration measurements via direct detection method is being developed at NASA Langley Research Center. This active remote sensing instrument will provide an alternate approach of measuring atmospheric $\mathrm{CO}_{2}$ concentrations with significant advantages. A high energy pulsed approach provides high-precision measurement capability by having high signal-to-noise ratio level and unambiguously eliminates the contamination from aerosols and clouds that can bias the IPDA measurement. Commercial, on the shelf, components are implemented for the detection system. Instrument integration will be presented in this paper as well as a background for $\mathrm{CO}_{2}$ measurement at NASA Langley research Center.
\end{abstract}

Keywords: Carbon dioxide, active remote sensing, integrated path differential absorption lidar

\section{INTRODUCTION}

Carbon dioxide $\left(\mathrm{CO}_{2}\right)$ is an important greenhouse gas that significantly contributes to the carbon cycle and global radiation budget on Earth. Generally, the $\mathrm{CO}_{2}$ role on Earth's climate is rather complicated due to different interactions with various climate components that include the atmosphere, the biosphere and the hydrosphere [1-3]. These interactions define $\mathrm{CO}_{2}$ sources and sinks that influence the gas transport fluxes worldwide. High uncertainties exist in quantifying $\mathrm{CO}_{2}$ sources and sinks mainly due to insufficient spacial and temporal monitoring of the gas. Understanding the interactions and transport of atmospheric $\mathrm{CO}_{2}$ around the Earth is critical for carbon cycle studies and climate predictions through environment models [1-12].

Historical $\mathrm{CO}_{2}$ concentration has been predicted through analyzing trapped gas released form ice cores obtained from Antarctic glaciers samples. Results indicated relatively stable atmospheric $\mathrm{CO}_{2}$ concentration that fluctuates between 180 and $290 \mathrm{ppm}$ over the past 650,000 years [4]. However, since the industrial revolution the gas concentration is increasing rapidly to a current level of $390 \mathrm{ppm}$ [5]. The recent $\mathrm{CO}_{2}$ high increase rate is attributed to human activities for different reasons. One reason is the temporal isotopic signature of fossil fuel burning that exists in current atmospheric $\mathrm{CO}_{2}$ [6]. Another reason is the spatially higher $\mathrm{CO}_{2}$ concentration in the Northern Hemisphere, where most of the land mass and human activities occur, than the Southern Hemisphere with higher ocean coverage [11]. Atmospheric $\mathrm{CO}_{2}$ observations made over the past four decades shows similar trends between the gas concentration in the atmosphere $\mathrm{CO}_{2}$ and industrial emission [3]. These evidences led to extensive efforts worldwide for monitoring atmospheric $\mathrm{CO}_{2}$ through various techniques including in-situ and passive sensors.

$\mathrm{CO}_{2}$ in-situ sensors have been used continuously on towers, aircraft and balloons for several decades for monitoring the gas concentration. Results from tower sensors indicated the existence of seasonal and diurnal cycles of the $\mathrm{CO}_{2}$ concentration, both related to biosphere activities. Seasonal cycles alternate the biosphere from source to sink between winter and summer respectively. Diurnal cycles respond to the respiration and photosynthesis activities [7]. For example, in a forested area study, tower in-situ sensors indicated a variation in the $\mathrm{CO}_{2}$ diurnal cycle of 5 to $40 \mathrm{ppm}$ between winter and summer seasons, respectively $[8,9]$. On the other hand, aircraft in-situ sensors identified that the $\mathrm{CO}_{2}$ con-

*upendra.n.singh@nasa.gov; phone 757-864-1570; fax 757-864-7798 
centration and its seasonal cycle depends on latitude [10,11]. Results confirmed higher $\mathrm{CO}_{2}$ concentration in the northern Hemisphere compared to the Southern, with higher seasonal cycle amplitude [11]. Balloons and aircraft sensors also were used to sample CO2 concentrations versus altitude [11, 12]. Results indicated constant CO2 concentration with respect to altitude up to a level where global air transport patterns take place [11]. Generally, $\mathrm{CO}_{2}$ in-situ sensors coverage is limited due to inadequate sampling sites and time. Thus, it is required to have more rapid and accurate $\mathrm{CO}_{2}$ monitoring with higher uniform coverage and high resolution. This was addressed by many international satellite missions.

Satellites passive remote sensing of $\mathrm{CO}_{2}$ concentrations provide improved spatial and temporal coverage compared to the surface in-situ networks. Satellites offered many advantages including the ability of continuously measuring $\mathrm{CO} 2$ in tropical regions and over southern oceans [1-3]. Present satellite instruments monitoring $\mathrm{CO}_{2}$ from space include SCIAMACHY, TES, AIRS, IASI and GOSAT [13-17]. To focus only on $\mathrm{CO}_{2}$ and address the issue of the gas sources and sinks, OCO-2 is fully dedicated for $\mathrm{CO}_{2}$ monitoring [18]. Generally, satellite passive remote sensing relies on either solar radiation (shortwave infrared) or thermal radiation from Earth. Some of these systems have shown the potential to meet the spatial coverage to improve $\mathrm{CO}_{2}$ flux estimates on continental scales. However, they are unable to meet the accuracy required to aid in better quantifying the terrestrial sources and sinks. Generally satellite passive systems have limitations. For example shortwave infrared instruments are limited by their reliance on solar illumination which restricts their orbits and latitudinal coverage. On the other hand, thermal infrared systems are not sensitive to the lower atmosphere where the largest $\mathrm{CO}_{2}$ interactions occur. Furthermore, passive remote sensing systems involve retrieval complexities which suffer from aerosol and cloud contamination and radiation path length uncertainties [2-3, 19]. Active remote sensing of $\mathrm{CO}_{2}$ is an alternative technique that has the potential to overcome the limitation of the passive sensors.

Active remote sensing of $\mathrm{CO}_{2}$ has been demonstrated using the differential absorption lidar (DIAL) technique [20-30]. Both 1.6 and $2.0 \mathrm{um}$ are considered suitable for atmospheric $\mathrm{CO}_{2}$ measurements due to the existence of distinct absorption feathers for the gas at these particular wavelengths. Although $\mathrm{CO}_{2}$ DIAL systems demonstrations were provided for systems validity from ground or airborne, a complete $\mathrm{CO}_{2}$ DIAL mission that contributes to the science community has not been established [3]. A number of worldwide teams have been engaged in developing $\mathrm{CO}_{2}$ DIAL instrument using different laser transmitters and detection methods. In France, a $\mathrm{CO}_{2}$ DIAL was developed based on 2.0$\mu \mathrm{m}$ pulsed crystal-open path cavity transmitter and heterodyne detection [20]. In Germany a 1.6-um pulsed optical parametric oscillator transmitter with direct detection has been developed [21]. In Japan similar systems were developed for ground based-measurement [27, 28]. In the USA, the National Research Council (NRC) Decadal Survey recommended an active laser-based $\mathrm{CO}_{2}$ mission, "Active Sensing of $\mathrm{CO}_{2}$ Emissions over Night, Days, and Seasons (ASCENDS)", to dramatically increase our understanding of $\mathrm{CO}_{2}$ sources, sinks, and fluxes worldwide [1]. Research groups at NASA are currently involved in developing different $\mathrm{CO}_{2}$ DIAL instruments. Two of these instruments operate at $1.6 \mu \mathrm{m}$ have been developed and deployed as airborne systems for atmospheric $\mathrm{CO}_{2}$ column measurements [22, 2526]. One instrument is based on an intensity modulated continue wave (CW) approach [25-26], the other on a high pulse repletion frequency (PRF), low pulse-energy approach [22]. These airborne $\mathrm{CO}_{2}$ DIAL systems operating at $1.57-\mu \mathrm{m}$ utilize mature laser and detector technologies by taking advantage of the technology development outcomes in the telecom industry. $\mathrm{CO}_{2}$ DIAL operating in the $2-\mu \mathrm{m}$ band offer better near-surface $\mathrm{CO}_{2}$ measurement sensitivity due to the intrinsically stronger absorption lines. Using a $2.05-\mu \mathrm{m} \mathrm{CW}$ laser absorption spectrometer employing coherent detection method, airborne measurements of $\mathrm{CO}_{2}$ column abundance has been demonstrated [24]. This paper focuses on the current role played by NASA Langley Research Center (LaRC) in developing a 2- $\mu$ m pulsed DIAL systems for monitoring atmospheric $\mathrm{CO}_{2}$ [23, 29-30]. For more than 15 years, NASA LaRC has been involved in maturing the transmitter technology and system capabilities that are focused onto meeting the science objective of the $\mathrm{CO}_{2}$ measurement described by the decadal survey and A-Scope [1,2]. Furthermore, the requirement and the potential of scaling such technology to a space mission will be addressed.

\section{SINGLE-PULSED 2-MICRON $\mathrm{CO}_{2}$ DIAL SYSTEMS DEMONSTRATION}

Atmospheric $\mathrm{CO}_{2}$ DIAL measurement using single-pulse 2- $\mu \mathrm{m}$ laser have been demonstrated by NASA LaRC [23, 2930]. The wavelength of the output laser pulses alternate between on-line and off-line positions at a relatively slow rate (5-10 Hz). Using heterodyne detection, $\mathrm{CO}_{2}$ DIAL measurements were attempted based on a $90 \mathrm{~mJ}, 140 \mathrm{~ns}, 5 \mathrm{~Hz}$ pulsed Ho:Tm:LuLiF laser transmitter. The laser transmitter adopted a wavelength control to precisely tune and lock the operating wavelength at any desired offset up to $2.9 \mathrm{GHz}$ from the center of a $\mathrm{CO}_{2}$ absorption line. Once detuned from 
the line center the laser wavelength is actively locked to keep the wavelength within $1.9 \mathrm{MHz}$ standard deviation about the set point. The wavelength controlled allows optimization of the $\mathrm{CO}_{2}$ optical depth for the DIAL measuring. The laser transmitter has been coupled with a coherent heterodyne receiver for measurements of $\mathrm{CO}_{2}$ concentration using aerosol backscatter. A byproduct of this system is the wind and aerosols measurements with the same lidar. This provides useful additional information on atmospheric structure. Range-resolved $\mathrm{CO}_{2}$ measurements were made with $<2.4 \%$ standard deviation using $500 \mathrm{~m}$ range bins and $6.7 \mathrm{~min}$ (1000 pulse pairs) integration time. Measurement of a horizontal column showed a precision of the $\mathrm{CO}_{2}$ concentration to $<0.7 \%$ standard deviation using a 30 min (4500 pulse pairs) integration time. Comparison with a collocated in situ sensor, as shown in figure 1, indicated the DIAL capability to measure the same trend of a diurnal variation and to detect shorter time scale $\mathrm{CO}_{2}$ perturbations. For vertical column measurements the lidar was setup at the WLEF tall tower site in Wisconsin to provide meteorological profiles and to compare the DIAL measurements with the in situ sensors distributed on the tower up to $396 \mathrm{~m}$ height. Assuming the DIAL column measurement extending from $153 \mathrm{~m}$ altitude to $1353 \mathrm{~m}$ altitude should agree with the tower in situ sensor at $396 \mathrm{~m}$ altitude, there was a $7.9 \mathrm{ppm}$ rms difference between the DIAL and the in situ sensor using a $30 \mathrm{~min}$ rolling average on the DIAL measurement as indicated in the same figure [23].

Detection technology usually limits the $\mathrm{CO}_{2}$ DIAL profiling capability at the $2-\mu \mathrm{m}$ wavelength. Therefore, $2-\mu \mathrm{m}$ phototransistors have been developed and integrated for the first time in lidar applications. This direct detection $2-\mu \mathrm{m}$ $\mathrm{CO}_{2}$ DIAL system was developed at NASA LaRC [29-30]. Initially, a backscatter lidar system has been demonstrated by utilizing the same $2-\mu \mathrm{m}$ single-pulsed tunable pulsed laser and the infrared phototransistor for the transmitter and the receiver, respectively. To validate the profiling capability of the system, the $2-\mu \mathrm{m}$ atmospheric backscatter profiles were compared to profiles obtained at 1 and $0.5 \mu \mathrm{m}$ using avalanche photodiode and photomultiplier tube, respectively. The 2$\mu \mathrm{m}$ system capability for atmospheric $\mathrm{CO}_{2}$ temporal profiling using DIAL was demonstrated. This was achieved by tuning the laser at slightly different wavelengths around the $\mathrm{CO}_{2} \mathrm{R} 22$ absorption line in the $2.05-\mu \mathrm{m}$ band as shown in figure 2 [30]. $\mathrm{CO}_{2}$ temporal profiles were also compared to in situ measurements. Preliminary results indicated average mixing ratios close to $390 \mathrm{ppm}$ in the atmospheric boundary layer with $3.0 \%$ precision. Field experiments were conducted at West Branch, Iowa, for evaluating the system for $\mathrm{CO}_{2}$ measurement by comparison with in-situ sensors. The NOAA's $\mathrm{CO}_{2}$ in-situ sensors were located on the WBI tower at 31, 99 and 379 m altitudes, besides the NOAA's aircraft was sampling at higher altitudes. Preliminary results, shown in figure 3, demonstrated the capabilities of the DIAL system in profiling atmospheric $\mathrm{CO}_{2}$ using the $2-\mu \mathrm{m}$ wavelength. One advantage of the DIAL system is the ability to perform integrated $\mathrm{CO}_{2}$ column measurements. This is demonstrated using data collected on June 26, 2008. On that day, weather conditions included continuous, variable altitude cirrus clouds, as indicated in the false color diagrams of figure 3. Vertical column integration was performed between the near-field high scattering from the

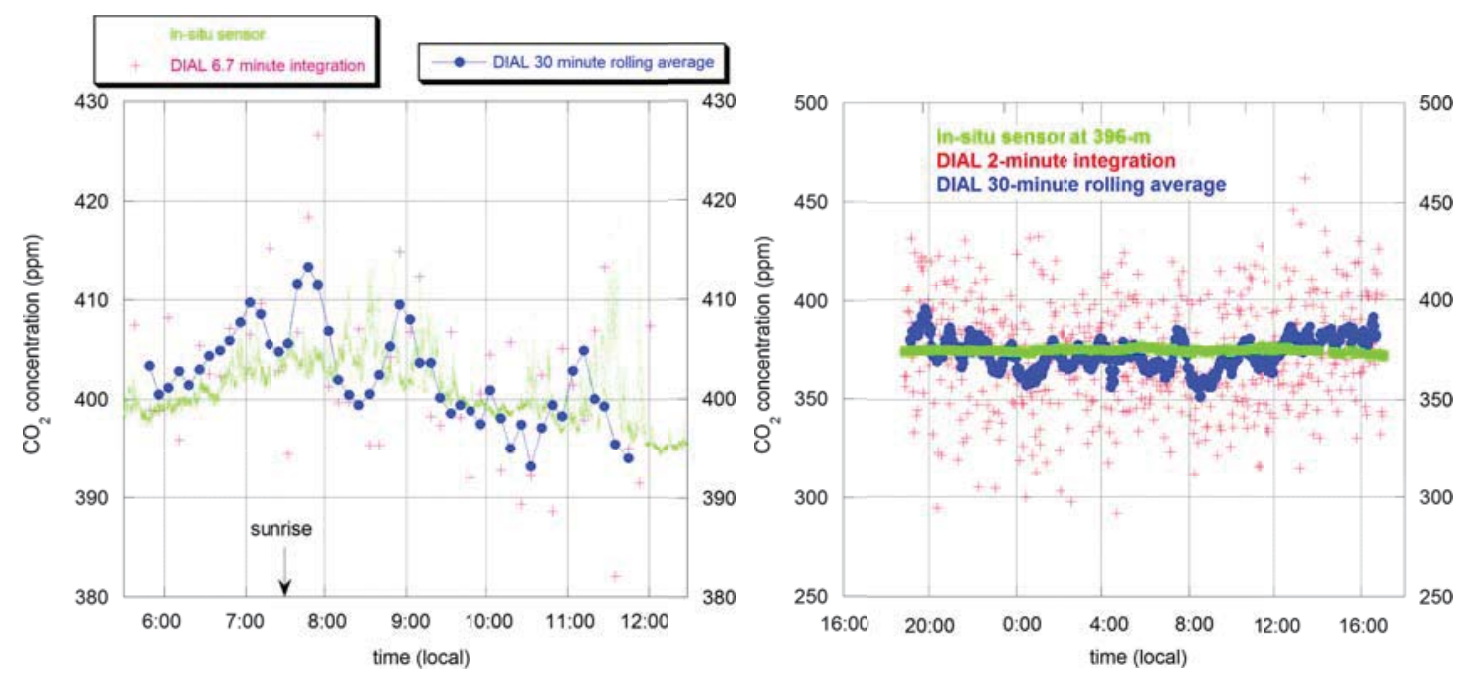

Figure 1. (Left) 2- $\mu \mathrm{m}$ heterodyne $\mathrm{CO}_{2}$ DIAL results compared to in situ sensor. Experiment was conducted on March 23, 2007 in Hampton, Virginia. The DIAL beam is pointing horizontally for a column measurement at the same altitude as the in situ sensor. (Right) Results from the same DIAL instrument compared to in situ measurements conducted on June 13-14, 2007 at the WLEF tower site. The in situ sensor is at 396m altitude. DIAL measurements are averaged over a vertical column extending from 153 to $1353 \mathrm{~m}$ altitude [23]. 


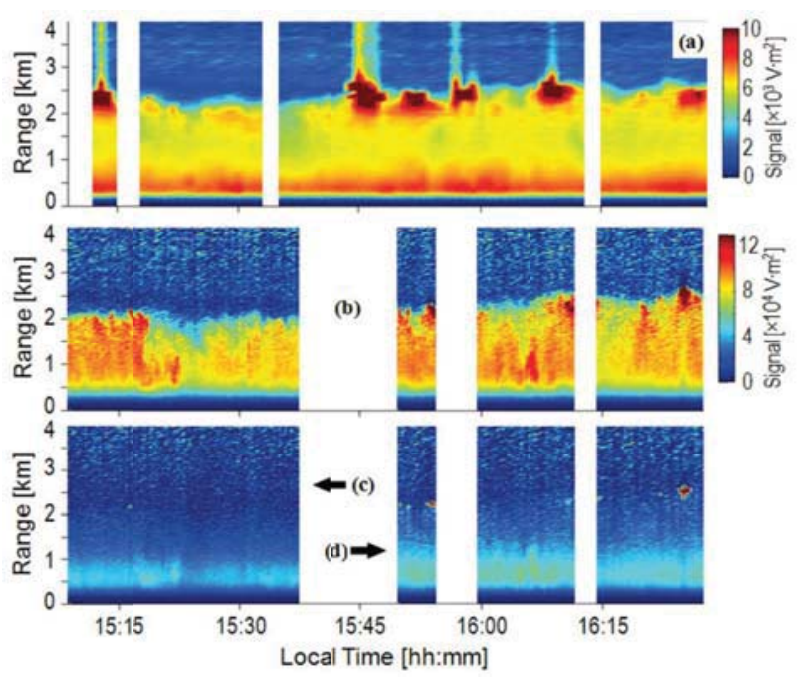

Figure 2. False color diagrams for the near-field boundary layer profiles measured on May 19, 2008 using lidar instruments operating at (a) $1064 \mathrm{~nm}$ and the 2- $\mu \mathrm{m}$ lidar operating in DIAL mode at (b) off-line $2053.449 \mathrm{~nm}$ and (c) $2.15 \mathrm{GHz}$ sideline and (d) $2.80 \mathrm{GHz}$ side-line. Time discontinuity in the data is attributed to system adjustments [30].
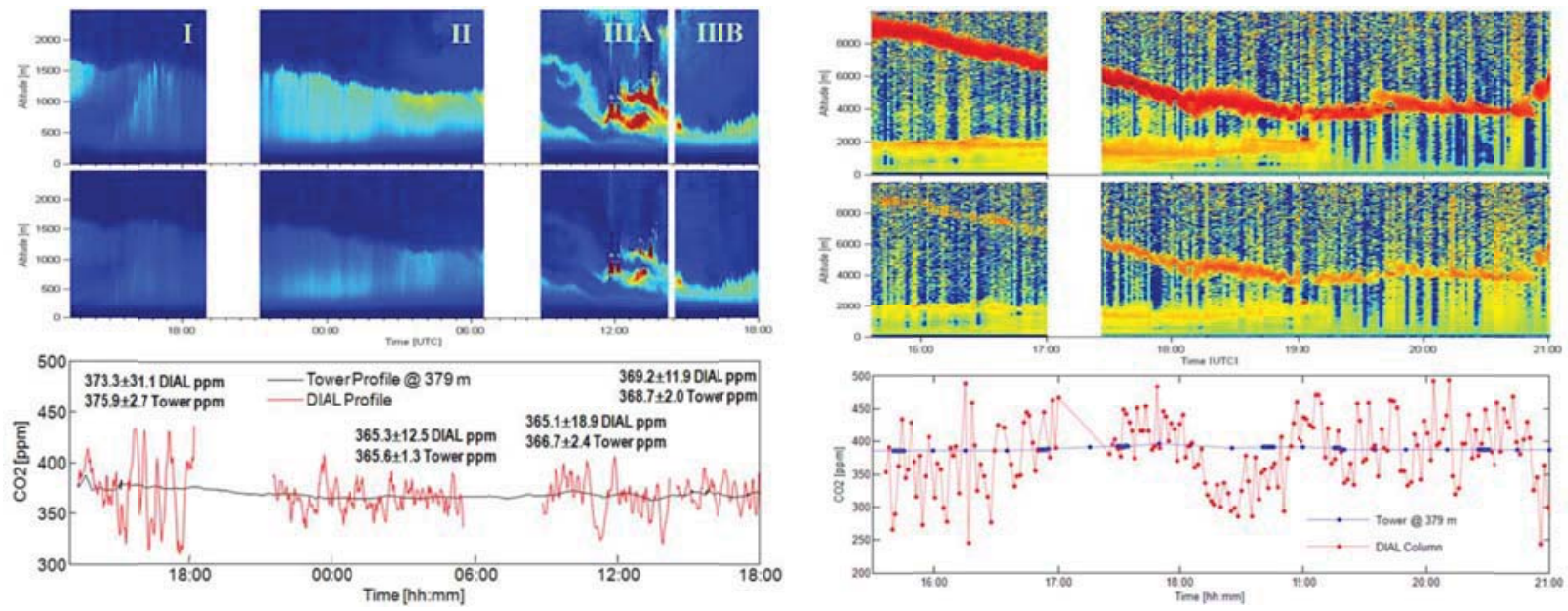

Figure 3. (Left) False color diagrams for the off-line (top) and side-line (middle) of the range corrected signal profiles. The data was collecting from the morning of July 5th till the afternoon of July 6th, 2008 with $2.80 \mathrm{GHz}$ (sections I and IIIB) and 2.15 (sections II and IIIA) tuning. The calculated $\mathrm{CO}_{2}$ mixing ratio of the DIAL and $379 \mathrm{~m}$ tower sensor are compared in the bottom. (Right) False color diagrams for the log of the range corrected off-line and side-line profiles (top and middle) from measurements on June 26, 2008. The calculated effective average $\mathrm{CO}_{2}$ mixing ratio of the DIAL and tower sensor are compared in the bottom [29].

boundary layer and the far-field scattering from the cloud. The measurement results are shown in the same figure [29].

The conducted single-pulse 2- $\mu \mathrm{m} \mathrm{CO}_{2}$ DIAL experiments point out several system improvements that would enhance the measurement capability. First, the selected target $\mathrm{CO}_{2} \mathrm{R} 22$ line includes high water vapor interference that coexists at the same operating wavelength. Operating on the $\mathrm{CO}_{2} \mathrm{R} 30$ line potentially increases the system sensitivity while reducing the water vapor interference close to zero. Besides, locking the off-line position, as well as the on-line, increases the accuracy of the measurement by reducing laser jitter errors. These improvements required upgrading the 2$\mu \mathrm{m}$ laser transmitter technology. Another upgrade that is necessary for airborne DIAL systems is the pulse repetition rate. With single-pulse, $5 \mathrm{~Hz}$ transmitter, the on-line and off-line pulses are separated by a long period resulting in inconsistent volume sampling between the two wavelengths. This led to the adoption of the high repetition rate doublepulsed $2-\mu \mathrm{m}$ laser transmitter. 


\section{DOUBLE-PULSED $\mathrm{CO}_{2}$ IPDA AIRCRAFT DEVELOPMENT}

Double-pulse 2- $\mu \mathrm{m}$ lasers have been demonstrated with energy as high as $600 \mathrm{~mJ}$ and up to $10 \mathrm{~Hz}$ repetition rate [31]. The two laser pulses are separated by $150 \mu$ s and can be tuned and locked separately. Applying double-pulse laser in DIAL system enhances the $\mathrm{CO}_{2}$ measurement capability by increasing the overlap of the sampled volume between the on-line and off-line [32]. To avoid detection complicity, integrated path differential absorption (IPDA) lidar provides higher signal-to-noise ratio measurement compared to conventional range-resolved DIAL. Rather than weak atmospheric scattering returns, IPDA rely on the much stronger hard target returns that is best suited for airborne platforms. In addition, the IPDA technique measures the total integrated column content from the instrument to the hard target but with weighting that can be tuned by the transmitter. Therefore, the transmitter could be tuned to weight the column measurement to the surface for optimum $\mathrm{CO}_{2}$ interaction studies or up to the free troposphere for optimum transport studies. Currently, NASA LaRC is developing and integrating a double-Pulsed 2- $\mu \mathrm{m}$ direct detection IPDA lidar for $\mathrm{CO}_{2}$ column measurement from an airborne platform [32].

\subsection{Transmitter Development}

The compact, rugged, highly reliable $\mathrm{CO}_{2}$ IPDA laser transmitter is based on the Ho:Tm:YLF high-energy 2- $\mu \mathrm{m}$ pulsed laser technology. This laser transmitter is side pumped by AlGaAs diode arrays at $792 \mathrm{~nm}$. It is capable of generating $100 \mathrm{~mJ}$ at $10 \mathrm{~Hz}$. The laser transmitter is designed to be operated in a unique double pulse format to mitigate the effect of the surface reflection difference between the on-and-off line pulses on the precision of the IPDA measurement. When the Ho upper laser level population reaches its maximum value at the end of the pump cycle, a first Q-switched pulse is generated which extracts the energy stored in the $\mathrm{Ho}^{5} \mathrm{I}_{7}$ upper laser level, resulting in a sharp decrease in the upper laser level population. Then, a new population equilibrium between the $\mathrm{Tm}^{3} \mathrm{~F}_{4}$ and $\mathrm{Ho}^{5} \mathrm{I}_{7}$ manifolds is established by energy transfer from the excited Tm ions towards Ho ions even though the pump no longer exists. The population at Ho upper laser level ${ }^{5} \mathrm{I}_{7}$ comes to its second maximum about 150 micro after the first pulse. The second Q-switch pulse is triggered at this moment resulting in the desired double pulse operation with energy of up to $40 \mathrm{~mJ}$ depending on the time interval from the first pulse. A unique feature of this laser operation is that it provides two Q-switched pulses with a single pump pulse due to the long upper laser lifetime.

The exact wavelengths of the pulsed laser transmitter are controlled by the wavelength control unit output. The first pulse and the second pulse are injection seeded alternately by the on-line frequency and the off-line frequency. All the optical mounts are custom designed with space heritage. They are designed to be adjustable and lockable and hardened to withstand vibrations that can occur in airborne operation. Figure 4 is a picture of the engineering packaged laser transmitter. This laser transmitter is $11.5 \times 26.5 \times 6.4$ inch $(29 \times 67.3 \times 16.5 \mathrm{~cm})$ in size, and weighted less than $701 \mathrm{bs}$.
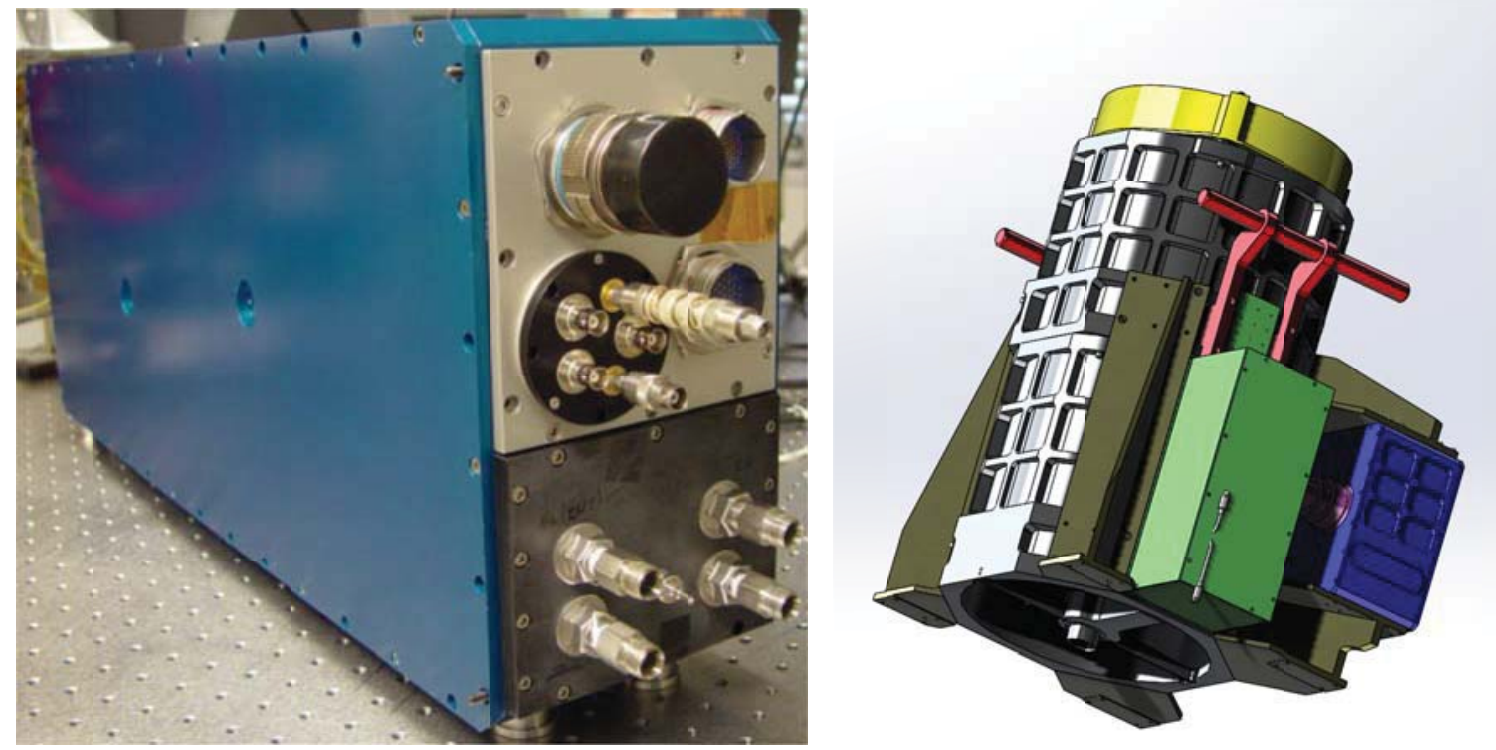

Figure 4. (Left) Packaged 2- $\mu \mathrm{m}$ double-pulsed $\mathrm{CO}_{2}$ IPDA laser transmitter. (Right) Integrated, 2- $\mu \mathrm{m}$, double-pulsed IPDA lidar for airborne $\mathrm{CO}_{2}$ measurement [32]. 


\subsection{Receiver Development}

The receiver telescope is a custom designed Newtonian type with $40 \mathrm{~cm}$ diameter aluminum primary mirror. The shape of the primary mirror is hyperbolic to minimize the aberration, so that the returning signal can be focused to less than $300 \mu \mathrm{m}$ diameter spot size compatible with selected detector. The telescope is designed to maintain the focus point position in the temperature range between 5 and $35{ }^{\circ} \mathrm{C}$. A $300 \mu \mathrm{m}$ diameter InGaAs pin photodiode (Hamamatsu; G5853) was selected for this mission. Detector characterization resulted in an NEP of $6.8 \times 10^{-14} \mathrm{~W} / \mathrm{Hz}^{0.5}$ at $30^{\circ} \mathrm{C}$ that is suited for the IPDA lidar application. After amplification the lidar signals are digitized and stored by a data acquisition unit. The data acquisition unit is based on two 12-bit digitizers (Agilent; DC252). One of which monitors the laser energy and the other for the lidar return. The system runs Microsoft XP with a 64-bit/66 MHz PCI bus, which is capable of transferring data at sustained rates up to $400 \mathrm{MB} / \mathrm{sec}$ to a host personal computer. The system is able to digitize a large amount of lidar return signal at a fast trigger rate with the given specifications. Figure 4 shows the mechanical assembly for the airborne integrated $2-\mu \mathrm{m}$ double pulsed $\mathrm{CO}_{2}$ IPDA instrument.

\subsection{Aircraft integration}

The compact IPDA lidar system is designed for integration into a small research aircraft such as the NASA B-200 or UC-12. By considering fitting the $\mathrm{CO}_{2}$ IPDA instrument into a B-200 aircraft platform, the completed lidar system shall be easily adapted to any other bigger aircraft such as DC-8 aircraft. The mechanical design of the $\mathrm{CO}_{2}$ IPDA lidar system is compact and light weighted to meet the payload requirements for the aircraft, simultaneously with any validation instruments. The lidar integration includes mechanical system design, fabrication, integration, testing and verification of system performance with respect to aircraft's flight loading profile. A mechanical supporting structure is being designed to integrate the transmitter, the telescope and receiver into an adjustable, yet rigid platform. The primary objective of this structure is to maintain alignment integrity throughout the operating flight envelope of the aircraft, and at the same time minimize aircraft vibration from adversely affecting the lidar measurements. The mechanical structure is optimized to satisfy the stiffness, mass and volume constraints of the aircraft. Figure 5 shows a preliminary design concept of the Transmitter-Telescope-Receiver Integrating Structure of the $\mathrm{CO}_{2}$ IPDA Lidar system as installed in a B200 aircraft. The optical portal has already been modified and installed to readily accept the lidar system as shown.

\subsection{Ground Testing}

The integrated lidar instrument will be tested in ground with horizontal target before the lidar instrument is integrated into the aircraft. The number density of $\mathrm{CO}_{2}$ along with pressure, temperature, and relative humidity information obtained from ancillary measurements from in situ sensors are used to retrieve dry $\mathrm{CO}_{2}$ mixing ratios. The data obtained during instrument testing will be evaluated, including comparisons to in situ instruments and evaluation of the data with respect to the weather and geographical environment. The goal will be evaluation of the performance of the lidar relative to the scientific measurement goals.

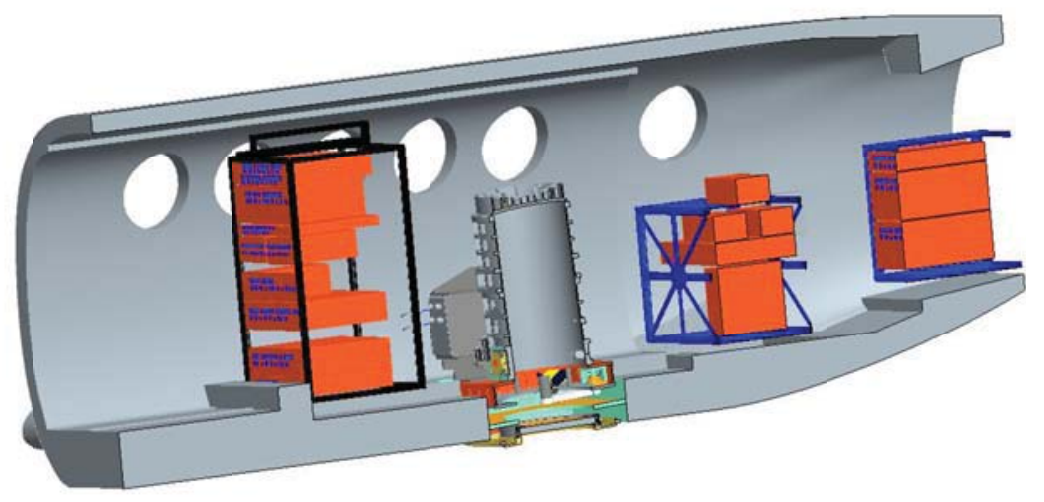

Figure 5. The 2- $\mu \mathrm{m} \mathrm{CO}_{2}$ double-pulsed IPDA system integration inside an aircraft, such as the NASA B-200 [32]. The IPDA instrument, shown in figure 4, (gray) is mounted on top of the aircraft bottom window. Assisting flight-qualified instrumentations (orange) are integrated on three racks (blue and black). 


\section{CONCLUSION}

Understanding atmospheric $\mathrm{CO}_{2}$ interactions and transport dynamics is important for studying carbon cycle and global radiation budget on Earth. In suit and satellite based passive remote sensors have several limitations that could be recovered with active remote sensors. $\mathrm{CO}_{2}$ active remote sensing has been demonstrated at NASA LaRC using the DIAL technique. The demonstration was limited to $2-\mu \mathrm{m}$ single-pulsed transmitter based on heterodyne and direct detection. This resulted in limited instrument capabilities in terms of measurement accuracy. Currently, NASA LaRC is developing a pulsed, high energy 2- $\mu \mathrm{m}$ IPDA lidar instrument for $\mathrm{CO}_{2}$ concentration measurement by implementing the integrated path differential absorption lidar technique (IPDA). The IPDA transmitter is a unique double-pulsed Ho laser capable of producing $\sim 100 \mathrm{~mJ}$ energy per pulse; and it is compactly and ruggedly packaged. High accuracy, stable and repeatable wavelength control and switching unit have been demonstrated. This unit is upgraded and engineering packaged to become a flyable unit. The IPDA also include a high quality 16 inch telescope and a commercial detector that has been purchased and characterized. Data acquisition unit, electrical control unit and thermal control unit are being developed and tested. The integrated IPDA lidar structure is being designed to fit in B-200 research aircraft. It is expected to provide a unique instrument tool for measuring atmospheric $\mathrm{CO}_{2}$ concentration. Field-testing of the developed instrument will be conducted from ground and aircraft. This unique capability could be scaled for future space missions.

\section{ACKNOWLEDGEMENT}

The authors would like to acknowledge NASA Earth Science Technology Office for their sustained support to the 2micron lidar technology development at NASA Langley Research Center. The author would like to thank Syed Ismail and Grady Koch of NASA Langley Research Center for supporting this effort.

\section{REFERENCES}

[1] National Research Council, "Earth Science and Applications from Space: National Imperatives for the Next Decade and Beyond", The National Academies Press, Washington DC, 2007.Booth, N. and Smith, A. S., [Infrared Detectors], Goodwin House Publishers, New York \& Boston, 241-248 (1997).

[2] P. Ingmann, P. Bensi, Y. Duran, A. Griva, and P. Clissold, "A-Scope - advanced space carbon and climate observation of planet earth", ESA Report for Assessment, SP-1313/1, 2008.

[3] J. Lawrence, "Differential absorption lidar for the total column measurement of atmospheric $\mathrm{CO}_{2}$ from space", Department of Physics and Astronomy Dissertation, University of Leicester, 2011.

[4] U. Siegenthaler, T. Stocker, E. Monnin, D. Luthi, J. Schwander, B. Stauffer, D. Ratynaud, J. Barnola, H. Fischer, V. Masson-Delmotte, and J. Jouzel, "Stable carbon cycle-climate relationship during the later Pleistocene", Science, 310, 1313, 2005.

[5] B. Barnola, M. Anklin, J. Porcheron, D. Raynaud, J. Schwander and B. Stauffer, " $\mathrm{CO}_{2}$ evolution during the last millennium as recorded by Antarctic and Greenland ice", Tellus, 47B, 264, 1995.

[6] J. Ehleringer, T. Cerling and M. Dearing, A history of atmospheric $\mathrm{CO}_{2}$ and its effects on plants animals and ecosystems, Springer, 2005.

[7] C. Keeling, T. Whorf, M. Wahlen and J. van der Plicht, "Interannual extremes in the rate of rise of atmospheric carbon dioxide since 1980", Nature, 375, 666, 1995.

[8] P. Bakwin, P. Tans, D. Hurst and C. Zhao, "Measurements of carbon dioxide on very tall towers: results of the NOAA/CMDL program", Tellus, 50B, 401, 1998.

[9] M. Hurwitz, D. Ricciuto, P. Bakwin, K. Davis, W. Wang, C. Yi and M. Butler, "Transport of carbon dioxide in the presence of storm systems over a Northern Wisconsin forest", Journal of the Atmospheric Sciences, 61, 607, 2004.

[10] T. Nakazawa, K. Miyashita, S. Aoki and M. Tanaka, "Temporal and spatial variations of upper tropospheric and lower stratospheric carbon dioxide", Tellus, 43B, 106, 1991.

[11]B. Anderson, G. Gregory, J. Collins, G. Sachse, T. Conway and G. Whiting, "Airborne observations of spatial and temporal variability of tropospheric carbon dioxide", Journal of Geophysical Research, 101, 1985, 1996.

[12] T. Nakazawa, T. Machida, S. Sugawara, S. Murayama, S. Morimoto, G. Hashida, H. Honda and T. Itoh, "Measurements of the stratospheric carbon dioxide concentration over Japan using a balloon-borne cryogenic sampler", Geophysical Research Letters, 22, 1229, 1995. 
[13]H. Bovensmann, J. Burrows, M. Buchwitz, J. Frerick, S. Noel, V. Rozanov, K. Chance and A. Goede, "SCIAMACHY: Mission objectives and measurement modes", Journal of the Atmospheric Sciences, 56, $127,1999$.

[14] S. Kulawik, D. Jones, R. Nassar, F. Irion, J. Worden, K. Bowman, T. Machida, H. Matsueda, Y. Sawa, S. Biraud, M. Fischer and A. Jacobson, "Characterization of Tropospheric Emission Spectrometer (TES) $\mathrm{CO}_{2}$ for carbon cycle science", Atmospheric Chemistry and Physics, 10, 5601, 2010.

[15]F. Chevallier, R. Engelen and P. Peylin, "The contribution of AIRS data to the estimation of $\mathrm{CO}_{2}$ sources and sinks", Geophysical Research Letters, 32, L23801, 2005.

[16] C. Crevoisier, A. Chedin, H. Matsueda, T. Machida, R. Armante and N. Scott, "First year of upper tropospheric integrated content of $\mathrm{CO}_{2}$ from IASI hyperspectral infrared observations", Atmospheric Chemistry and Physics, 9, 4797, 2009.

[17] J. Tadic, M. Loewenstein, C. Frankenberg, L. Iraci, E. Yates, W. Gore and A. Kuze, "A comparison of in-situ aircraft measurements of carbon dioxide to GOSAT data measured over Railroad Valley playa, Nevada, USA", Atmospheric Measurement Techniques Discussions, 5, 5641, 2012.

[18]D. Hammerling, A. Michalak and S. Kawa, "Mapping of $\mathrm{CO}_{2}$ at high spatiotemporal resolution using satellite observations: Global distributions from OCO-2", Journal of Geophysical Research, 117, D06306, 2012.

[19] K. Hungershoefer, F. Breon, P. Peylin, F. Chevallier, P. Rayner, A. Klonecki, S. Houweling, and J. Marshall, "Evaluation of various observing systems for the global monitoring of $\mathrm{CO}_{2}$ surface fluxes", Atmospheric Chemistry and Physics, 10, 10503, 2010.

[20]F. Gibert, P. Flamant, D. Bruneau and C. Loth, "Two-micrometer heterodyne differential absorption lidar measurements of the atmospheric $\mathrm{CO}_{2}$ mixing ratio in the boundary layer", Applied Optics, 45, 4448, 2006.

[21] A. Amediek, A. Fix, M. Wirth and G. Ehret, "Development of an OPO system at $1.57 \mu$ for integrated path DIAL measurement of atmospheric carbon dioxide", Applied Physics B, 92, 295, 2008.

[22] J. Abshire, H. Riris, G. Allan, S. Kawa, J. Mao, E. Wilson, M. Stephen, M. Krainak, X. Sun and C. Weaver, "Laser sounder approach for global measurements of tropospheric $\mathrm{CO}_{2}$ mixing ratio from space", $24^{\text {th }}$ International Laser Radar Conference, Boulder, Colorado, 2008.

[23] G. Koch, J. Beyon, F. Gibert, B. Barnes, S. Ismail, M. Petros, P. Petzar, J. Yu, E. Modlin, K. Davis and U. Singh, "Side-line tunable laser transmitter for differential absorption lidar measurements of $\mathrm{CO}_{2}$ : design and application to atmospheric measurements", Applied Optics, 47, 944, 2008.

[24] R. Menzies and G. Spiers, "Airborn laser absorption spectrometer for IPDA measurement of atmospheric effects on attainable precision and a technique for cloud and aerosol filtering”, $24^{\text {th }}$ International Laser Radar Conference, Boulder, Colorado, 2008.

[25] J. Dobler, F. Harrison, E. Browell, B. Lin, D. McGregor, S. Kooi, Y. Choi and S. Ismail, “Atmospheric CO $\mathrm{CO}_{2}$ column measurements with an airborne intensity-modulated continuous wave $1.57 \mu \mathrm{m}$ fiber laser lidar", Applied Optics, 52, $2874,2013$.

[26] E. Browell, M. Dobbs, J. Dobler, S. Kooi, Y. Choi, F. Harrison, B. Moore and T. Zaccheo, "Airborne demonstration of 1.57-micron laser absorption spectrometer for atmospheric $\mathrm{CO}_{2}$ measurements", $24^{\text {th }}$ International Laser Radar Conference, Boulder, Colorado, 2008.

[27] S. Ishii, K. Mizutani, H. Fukuoka, T. Ishikawa, H. Iwai, P. Baron, J. Mendrok, Y. Kasai, T. Aoki, A. Sato, K. Asai and T. Itabe, "Development of 2 micron coherent differential absorption lidar", $24^{\text {th }}$ International Laser Radar Conference, Boulder, Colorado, 2008.

[28] D. Sakaizawa, C. Nagasawa, M. Abo, Y. Shibata and T. Nagai, “ Development of a $1.6 \mu$ m CO 2 DIAL transmitter using OPM-OPO”, $24^{\text {th }}$ International Laser Radar Conference, Boulder, Colorado, 2008.

[29] T. Refaat, S. Ismail, G. Koch, L. Diaz, K. Davis, M. Rubio, N. Abedin and U Singh, "Field testing of a two-micron DIAL system for profiling atmospheric carbon dioxide", $25^{\text {th }}$ International Laser Radar Conference, St. Petersburg, Russia, 2010.

[30] T. Refaat, S. Ismail, G. Koch, M. Rubio, T. Mack, A. Notari, J. Collins, J. Lewis, R. De Young, Y. Choi, N. Abedin and U. Singh, "Backscatter 2- $\mu$ m lidar validation for atmospheric $\mathrm{CO}_{2}$ differential absorption lidar applications", IEEE Transaction on Geoscience and Remote Sensing, 49, 572, 2011.

[31] J. Yu, A. Braud and M. Petros, “600-mJ, double-pulse 2- mm laser”, Optics Letters, 28, 540, 2003.

[32] J. Yu, M. Petros, K. Reithmaier, Y. Bai, B. Trieu, T. Refaat, M. Kavaya, U. Singh, S. Ismail, "A 2-micron pulsed integrated path differential absorption lidar development for atmospheric $\mathrm{CO}_{2}$ concentration measurements", $26^{\text {th }}$ International Laser Radar Conference, Porto Heli, Greece, 2012. 